\title{
The power to detect artificial selection acting on single loci in recently domesticated species
}

Sten Karlsson ${ }^{1 *}$, Thomas Moen ${ }^{2,3+}$

\begin{abstract}
Background: An increasing number of aquaculture species are subjected to artificial selection in systematic breeding programs. Rapid improvements of important commercial traits are reported, but little is known about the effects of the strong directional selection applied, on gene level variation. Large numbers of genetic markers are becoming available, making it feasible to detect and estimate these effects. Here a simulation tool was developed in order to explore the power by which single genetic loci subjected to uni-directional selection in parallel breeding populations may be detected.

Findings: Two simulation models were pursued: 1) screening for loci displaying higher genetic differentiation than expected (high-F FT $_{\text {ST }}$ outliers), from neutral evolution between a pool of domesticated populations and a pool of wild populations; 2) screening for loci displaying lower genetic differentiation (low- $\mathrm{F}_{\text {ST }}$ outliers) between domesticated strains than expected from neutral evolution. The premise for both approaches was that the isolated domesticated strains are subjected to the same breeding goals. The power to detect outlier loci was calculated under the following parameter values: number of populations, effective population size per population, number of generations since onset of selection, initial $\mathrm{F}_{\mathrm{ST}}$, and the selection coefficient acting on the locus. Among the parameters investigated, selection coefficient, the number of generation since onset of selection, and number of populations, had the largest impact on power. The power to detect loci subjected to directional in breeding programmes was high when applying the between farmed and wild population approach, and low for the between farmed populations approach.

Conclusions: A simulation tool was developed for estimating the power to detect artificial selection acting directly on single loci. The simulation tool should be applicable to most species subject to domestication, as long as a reasonable high accuracy in input parameters such as effective population size, number of generations since the initiation of selection, and initial differentiation $\left(\mathrm{F}_{\mathrm{ST}}\right)$ can be obtained. Identification of genetic loci under artificial selection would be highly valuable, since such loci could be used to monitor maintenance of genetic variation in the breeding populations and monitoring possible genetic changes in wild populations from genetic interaction between escapees and their wild counterpart.
\end{abstract}

\section{Findings}

\section{Context}

Massive parallel sequencing/re-sequencing technologies have already provided thousands or even tens of thousands of DNA markers for a number of species, while the genotyping of such numbers of markers is becoming routine due to microarray-based genotyping technologies. The possibilities offered by these developments

\footnotetext{
* Correspondence: sten.karlsson@nina.no

+ Contributed equally

${ }^{1}$ NOFIMA Marine, Arboretveien 6, N-1432 Ås, Norway

Full list of author information is available at the end of the article
}

have already been exploited in order to identify loci under natural selection through genome-wide scans [1]. Some studies have focused on selection due to domestication selection of livestock- (e.g. [2]) and plant species (reviewed in [3]). Only a very limited number of studies have targeted signatures of selection in the context of modern breeding programmes [4]. Such studies could, however, be useful in order to increase our understanding of the locus-level consequences of modern artificial selection. To what extent does, for example, artificial selection lead to significant changes in allele frequency at individual loci, and (implicitly) how likely is it that 
functional genetic variation may be lost due to artificial selection? The existence of several nearly isolated breeding populations, sharing the same breeding goals, provides opportunities for identifying parallel changes between populations. For aquaculture species only a few generations have passed since selective breeding began, possibly limiting the statistical power to detect selection at single loci. In this study, we wanted to estimate the power to detect selection at single loci as a function of effective population sizes, number of parallel populations, number of generations since onset of selection, selection intensity, and the initial genetic distance between populations.

\section{Computational methods}

Two different methods for detecting selection were considered: 1) detection of loci with lower-than-expected values of $F_{S T}$ between selectively bred aquaculture populations (hereafter referred to as farmed populations), and 2) detection of loci with higher-than-expected values of $\mathrm{F}_{\mathrm{ST}}$ between a pool of farmed populations and a pool of wild populations. For both methods, the power to detect selection was estimated by simulating a single, bi-allelic locus both in the absence and presence of selection. The simulation program was written in Python (v2.6), utilising simuPop, a library for general-purpose, individualbased, forward-time population genetics simulation [5]. The code may be found in Additional files: low_fst.txt and high_fst.txt. The parameter values were chosen to be relevant for populations of Atlantic salmon in Norway, the focus of our own research, but should match a wide range of aquaculture species. With some exceptions, the Atlantic salmon breeding programmes share the following features: 1) they have been running for 10 or fewer generations, 2) each breeding programme has four parallel year classes, 3) the populations are more or less isolated with little or no gene flow between year classes, and 4) effective population sizes typically lie in the range of 30-50 ([6], Karlsson et al, unpublished data). The breeding programmes were once established from different sets of Norwegian rivers, with some overlap between the different sets [7]. $\mathrm{F}_{\mathrm{ST}}$ values between wild Norwegian populations have been found to lie around 0.05 (allozymes [8,9], microsatellites [10-12]). (These results were backed up by our own data on four wild populations genotyped for 12 microsatellite loci and 13 wild populations genotyped for 4514 SNP loci (unpublished)). On this background, our default simulated data set consisted of 10 closed farm populations (low- FT $_{\text {ST }}$ outlier approach) or 10 closed farm populations and 10 wild populations (high- $\mathrm{F}_{\mathrm{ST}}$ outlier approach), each population having an effective population size of 50. Specifically, we assumed that (directional) selection is only occurring in the breeding programmes and that this selection is leading to convergent evolution among different breeding strains. In an evolutionary context we are thus interested in detecting low- F $_{\text {ST }}$ outlier loci, that will appear as low- $\mathrm{F}_{\mathrm{ST}}$ outliers when only different breeding strains are being studied, but as high- $\mathrm{F}_{\mathrm{ST}}$ outlier loci when a pool of breeding strains are compared with a pool of wild populations (where no selection is occurring). From now on these different approaches will be referred to as Low- and High- $\mathrm{F}_{\mathrm{ST}}$ outlier approaches, respectively. The base populations of farmed populations were assumed to be drawn from different rivers, so that $\mathrm{F}_{\mathrm{ST}}$ between farmed population at generation 0 (base population) would be similar to $\mathrm{F}_{\mathrm{ST}}$ between wild populations (default $\left.=0.05\right)$. Parameter values ( $\mathrm{Ne}$, number of populations, and start $\mathrm{F}_{\mathrm{ST}}$ ) were altered one at a time in order to assess the impact of the parameter on experimental power.

\section{Algorithm}

Two different approaches for the detection of outlier loci were investigated. The first approach was based on the detection of loci displaying lower-than-expected (under a null hypothesis of no selection) $\mathrm{F}_{\mathrm{ST}}$ values between farmed strains. The second approach was based on the detection of loci displaying higher-than-expected values of $\mathrm{F}_{\mathrm{ST}}$ between a pool of farmed populations and a pool of wild populations. For both approaches, a single bi-allelic locus was simulated with and without selection.

\section{Low- $F_{\text {ST }}$ outlier approach}

In each of 1000 iterations, a single overall allele frequency was first drawn randomly from a uniform distribution between 0 and $1 . \mathrm{N}_{\text {pop }}$ populations, each consisting of $\mathrm{N}_{\mathrm{e}}$ animals with a single diploid locus, were then formed. Half of the individuals were designated as males, the other half as females. Genotypes were assigned randomly to individual animals, given the overall allele frequency. Next, random mating was simulated in each population for a number of generations, until the $\mathrm{F}_{\mathrm{ST}}$ value between populations reached the wanted level for initial $\mathrm{F}_{\mathrm{ST}}\left(\mathrm{F}_{\mathrm{ST}(0)}\right)$. Following this initial phase, random mating with (alternative hypothesis) or without (null hypothesis) selection was applied for $\mathrm{N}_{\text {gen }}$ generations; selection was applied by defining different fitness values for the different genotypes (assuming no dominance). At the end of each iteration, $\mathrm{F}_{\mathrm{ST}}$ between populations [13] was calculated. This process was iterated 1000 times without selection in order to generate a distribution of $\mathrm{F}_{\mathrm{ST}}$ under the null hypothesis, and 1000 times with selection in order to generate a distribution of $\mathrm{F}_{\mathrm{ST}}$ under the alternative hypothesis. Finally, the power to detect outlier loci was calculated. The power was defined as the fraction of the $\mathrm{F}_{\mathrm{ST}}$-distribution generated under the alternative hypothesis (i.e. under selection) that was lower than the $5 \%$ percentile of the 
$\mathrm{F}_{\mathrm{ST}}$-distribution generated under the null hypothesis (i.e. without selection). The Python code can be found in Additional file 1.

\section{High- $F_{S T}$ outlier approach}

In each of 1000 iterations, a single overall allele frequency was first drawn randomly from a uniform distribution between 0 and $1 . \mathrm{N}_{\text {pop }}$ " 2 populations, each consisting of $\mathrm{N}_{\mathrm{e}}$ animals with a single diploid locus, were then formed. Half of the individuals were designated as males, the other half as females. Genotypes were assigned randomly to individual animals, given the overall allele frequency. Random mating was simulated in each population for a number of generations, until the $F_{\mathrm{ST}}$ value between populations reached the wanted level for initial $\mathrm{F}_{\mathrm{ST}}\left(\mathrm{F}_{\mathrm{ST}(0)}\right)$. The populations were then split into two sets of equal size, representing farmed and wild populations. For the farmed populations, random mating with (alternative hypothesis) or without (null hypothesis) selection was simulated for $\mathrm{N}_{\text {gen }}$ generations. For the wild populations, random mating without selection was simulated for $\mathrm{N}_{\text {gen }}$ generations, but the size of each population was first increased to 500 in order to minimise the effect of drift in wild populations. At the end of each iteration, the populations were merged into one farmed and one wild 'metapopulation' and $\mathrm{F}_{\mathrm{ST}}$ between these metapopulations was calculated. This process was iterated 1000 times without selection in order to generate a distribution of $\mathrm{F}_{\mathrm{ST}}$ under the null hypothesis, and 1000 times with selection in order to generate a distribution of $\mathrm{F}_{\mathrm{ST}}$ under the alternative hypothesis. Finally, the power to detect outlier loci was calculated. The power was defined as the fraction of the $\mathrm{F}_{\mathrm{ST}}$-distribution generated under the alternative hypothesis (i.e. under selection) that was higher than the $95 \%$ percentile of the $\mathrm{F}_{\mathrm{ST}}$-distribution generated under the null hypothesis (i.e. without selection). The Python code can be found in Additional file 2.

\section{Testing}

With default parameter values, the power to detect non-neutral loci among breeding populations (low- $\mathrm{F}_{\mathrm{ST}}$ outliers) was found to be very low, except for extremely large selection coefficients, while relatively small or moderate selection coefficients were found to be sufficient for detecting non-neutral loci, when comparing farmed and wild population (high- $\mathrm{F}_{\mathrm{ST}}$ outliers) (Figure 1).

The power to detect high- $\mathrm{F}_{\mathrm{ST}}$ outliers rapidly increased, and was large for moderate and large selection coefficients, when the effective population size, number of populations and number of generation passed reached 40,5, and 10, respectively. Power and initial $\mathrm{F}_{\mathrm{ST}}$ was negatively correlated, with a rapid decline

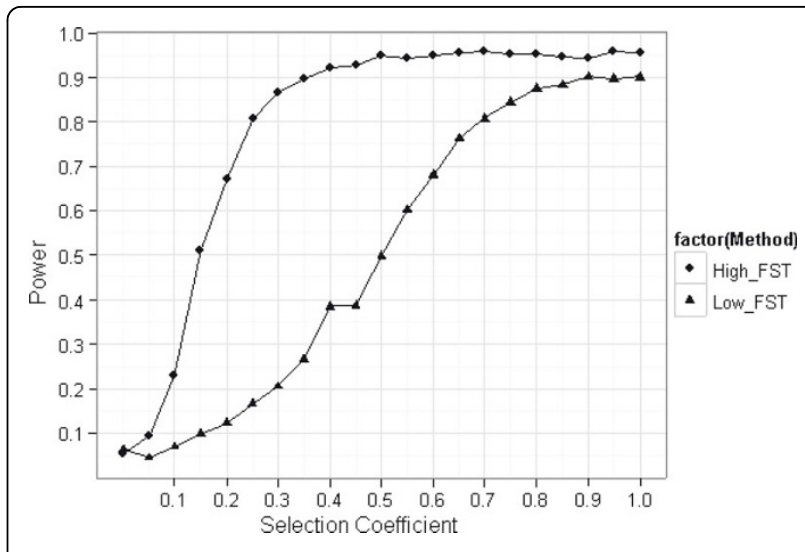

Figure 1 Comparison between low- $\mathrm{F}_{\mathrm{ST}}$ and high- $\mathrm{F}_{\mathrm{ST}}$ outliers approaches for detecting non-neural loci in domesticated populations. Power to detect low- $\mathrm{F}_{\text {ST }}$ outliers and high- $\mathrm{F}_{\text {ST }}$ outliers as a function of selection coefficient. Effective population size is 50 . Number of populations is 10 . Number of generations is 10 . Initial $F_{\text {ST }}$ is 0.05 . Number of iterations is 1000 .

in power with an increasing initial $\mathrm{F}_{\mathrm{ST}}$. The power to detect weak selection $(s=0.05)$ was close to zero regardless of effective population size, number of populations, and initial $\mathrm{F}_{\mathrm{ST}}$, but increased with an increasing number of generations since the establishment of the breeding populations (Figure 2).

The power to detect low- $\mathrm{F}_{\mathrm{ST}}$ outliers was not affected by increasing effective population size, or by the initial $\mathrm{F}_{\mathrm{ST}}$. The largest effect on the power was observed from increasing the number of populations and number of generations (Figure 3).

\section{Discussion and future development}

This study was undertaken as a preparatory step preceding an empirical study seeking to identify (markers for) loci under artificial selection in Norwegian Atlantic salmon breeding programmes. Our motivation for identifying such loci was fourfold: 1) they could potentially serve as universal markers of farmed versus wild Atlantic salmon, 2) they could also be used to elucidate any phenotypic changes occurring in wild salmon as a result of wild-to-farm gene flow, 3) the results could be used to predict to which extent functional loci are likely to be lost due to ongoing artificial selection, and 4) the results could contribute to the identification of loci controlling phenotypic traits in Atlantic salmon. The motivations and the approaches to identify non-neutral loci presented here may also apply to other aquaculture species [14], many of which might escape and interact with their wild counterparts (e.g. common carp [15], tench [16], Atlantic cod [17], Chinook salmon [18], clam [19], Chinese fresh water pearl [20]).

While the infinitesimal model of quantitative genetics assume than complex traits are controlled by many 


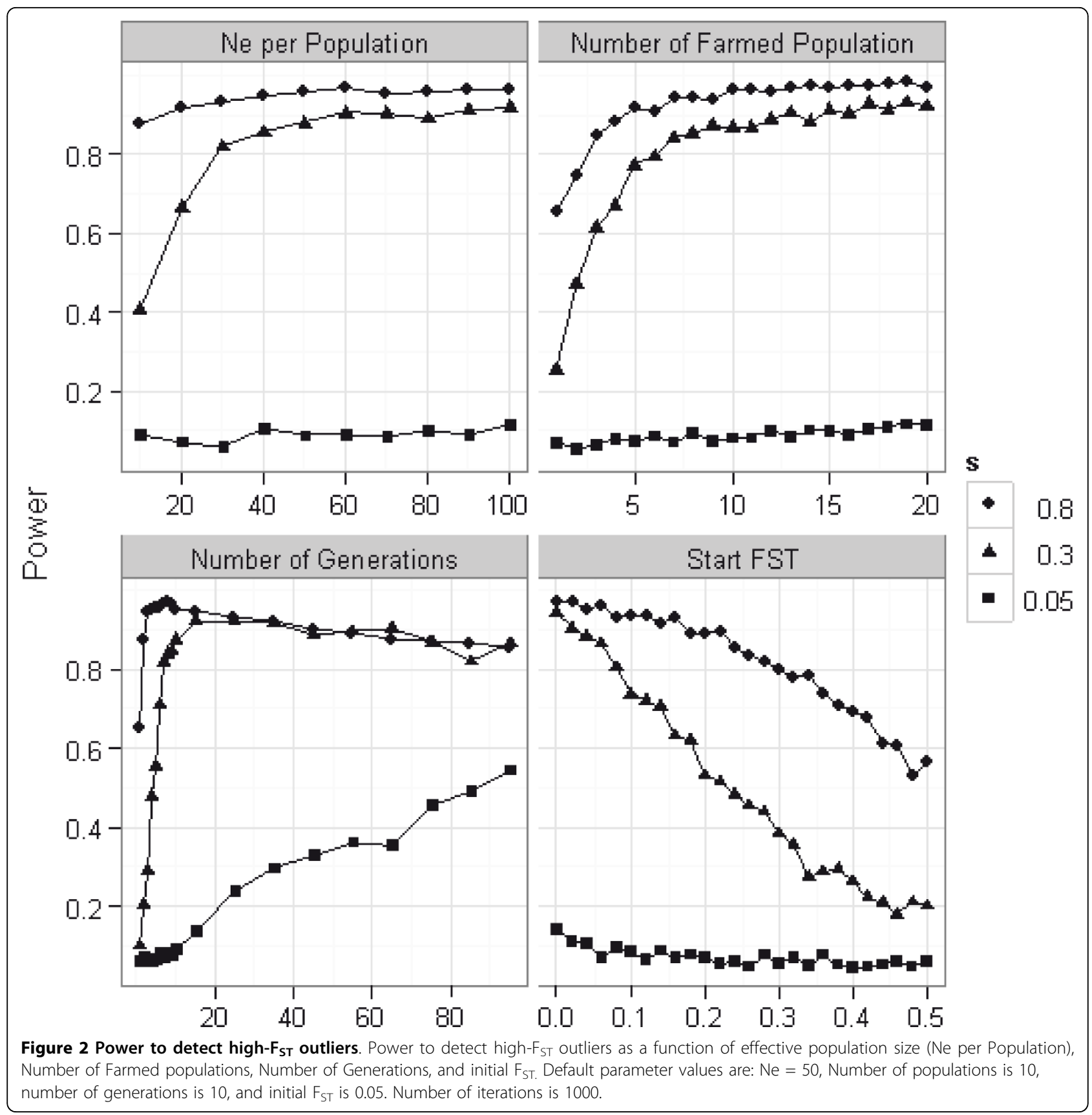

genes with small individual effects, indicating that a study such as this one is futile, experimental results show that some (assumed to be complex) traits are controlled by only a small number of genes. As a notable example, in two independent experiments, both with considerable statistical power, Houston et al. [21] and Moen et al. [22] identified one and the same QTL controlling the bulk of genetic variation in resistance to the viral disease infectious pancreatic necrosis (IPN) in Atlantic salmon. Many different tests for detecting selection at individual loci have been proposed in the literature (reviewed in [23]). Some of these test for deviation from the neutral expectation of balance between mutation and genetic drift (e.g. Ewens-Watterson homozygosity test [24,25], Tajima's D-test [26], Fu's Fs test [27]), while others test for regions containing long haplotypes of high frequency, indicative of selective sweeps $[28,29]$. We believe that these two groups of methods to be of little relevance for the current study, since i) the mutation-drift balance is not relevant on the time scale we are addressing ( $<10$ generations), and since ii) the selection is most likely to have been acting 


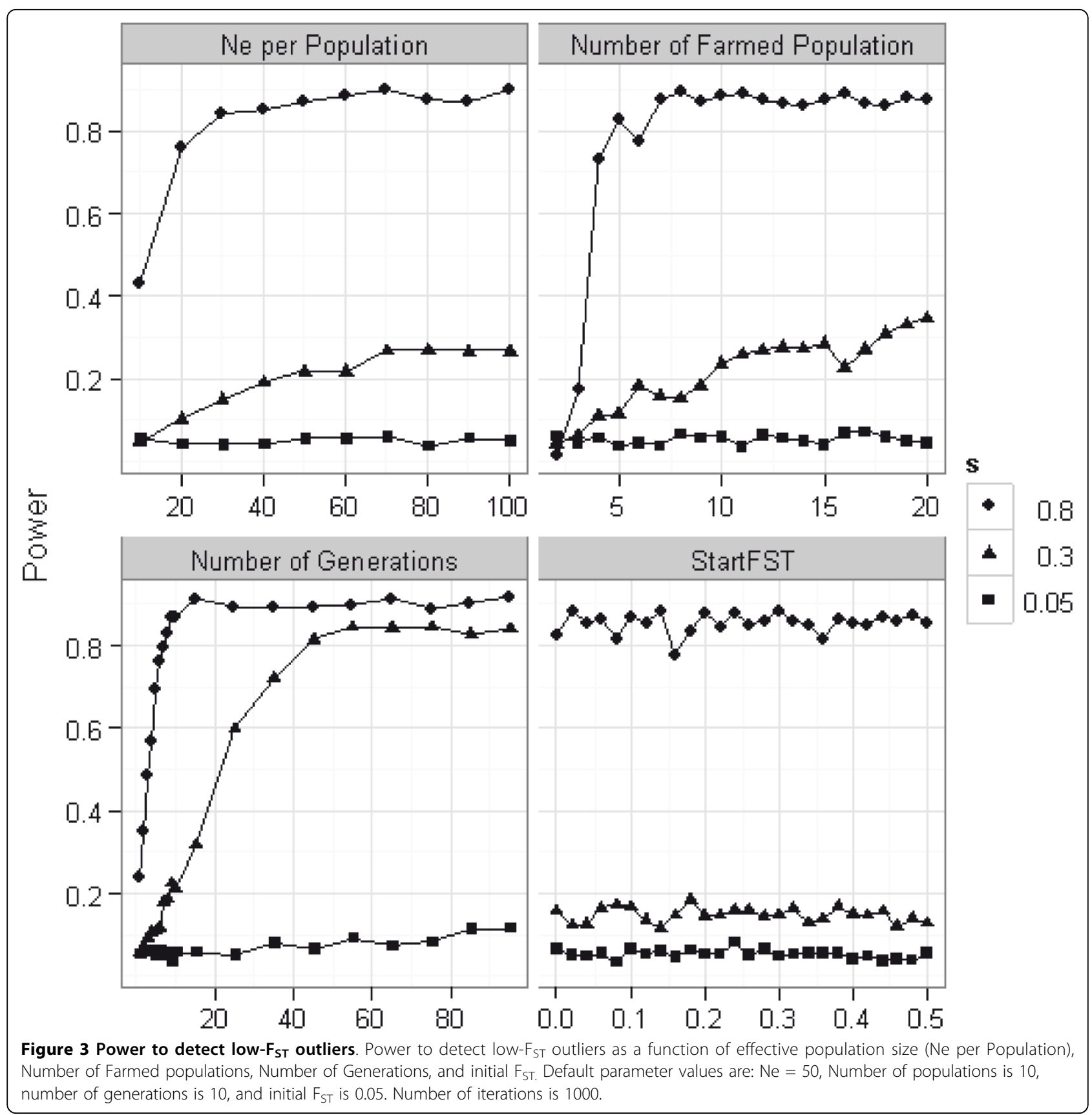

on standing variation, so that long-range extended haplotypes are not likely to be observed ([1] and references therein). While previously developed methods for testing outlier levels of $F_{\mathrm{ST}}$ between populations or within the same population sampled at different times [30-32] rely solely on observed genetic data for creating an expected $\mathrm{F}_{\mathrm{ST}}$ distribution to which the observed data may be compared, the method presented in this study take advantage of important prior knowledge to strengthen the power for detecting outlier loci in a selective breeding context. By utilizing knowledge of known effective population size, number of populations and time since the onset of directional selection, we believe a more accurate (and higher power) expected neutral distribution is obtained. We have therefore taken a more simplistic approach, assuming that selection will be detected through the comparison of differences in $\mathrm{F}_{\mathrm{ST}}$ between populations under (uni-) directional selection or between a selected and an unselected 'metapopulation'. We have further assumed that selection is acting directly upon the locus that is observed, whereas in practice one would more likely be observing a loci 
closely linked to (and in linkage disequilibrium (LD) with) that locus. As such, we describe best-case scenarios with regard to identifying loci under selection. Power will be lost due to incomplete LD between the observed marker and the locus under selection, but the amount of power lost will vary dependent on species and the marker density used in any given experiment.

The relevance of the power estimates presented here to a real experiment will depend upon how realistic the parameter values are. In addition to the selection coefficient, the number of populations and the number of generations since onset of selection were found to have the largest effect on power. These parameters are usually known for most breeding programs. An accurate estimate of the effective population size may be difficult to obtain unless a full pedigree is available. However, our simulations were robust against varying effective population sizes for Ne larger than 40 . The results show that the approaches presented here are not suitable for detecting loci subjected to weak selection, unless many generations (> 75) have passed since the onset of artificial selection. Quantitative Trait Loci (QTL) mapping is used for finding markers linked to commercially important traits; although QTL studies are powerful in linking non-neutral markers to phenotypic trait, the studies are restricted to the study of predefined traits, and are therefore not suitable for screening the whole genome for non-neutral loci influencing any trait under artificial selection. The approaches presented in the present study enable future screening of whole genomes for signatures of artificial selection.

\section{Additional material}

Additional file 1: High-Fst. Python code for simulation of power for high-fst outlier approach

Additional file 2: Low-Fst. Python code for simulation of power for low-Fst outlier approach

\begin{abstract}
Acknowledgements
This paper is a contribution from the project "Genomics as a tool for detecting selection in farm Atlantic salmon and interactions between escaped and farmed wild salmon" funded by the Research Council of Norway (NFR FUGE grant no. 175130).
\end{abstract}

\section{Author details}

${ }^{1}$ NOFIMA Marine, Arboretveien 6, N-1432 Ås, Norway. ${ }^{2}$ Aqua Gen AS, Postboks 1240, 7462 Trondheim, Norway. ${ }^{3}$ CIGENE, Arboretveien 6, N-1432 Ås, Norway.

\section{Authors' contributions}

TM and SK contributed equally in the design of the simulation models and in writing the manuscript. The programming work was done by TM. SK run the simulations and created the figures. Both authors approved of the manuscript.

\section{Competing interests}

The authors declare that they have no competing interests.

Received: 29 June 2010 Accepted: 26 August 2010

Published: 26 August 2010

\section{References}

1. Hancock AM, Di Rienzo A: Detecting the Genetic Signature of Natural Selection in Human Populations: Models, Methods, and Data. Annu Rev Anthropol 2008, 37:197-217.

2. Consortium TBH: Genome-Wide Survey of SNP Variation Uncovers the Genetic Structure of Cattle Breeds. Science 2009, 324:528-532.

3. Purugganan MD, Fuller $\mathrm{DQ}$ : The nature of selection during plant domestication. Nature 2009, 457:843-848.

4. Hayes BJ, Chamberlain AJ, MacEachern S, Savin K, McPartlan H, MacLeod I, Sethuraman L, Goddard ME: A genome map of divergent artificial selection between Bos taurus dairy cattle and Bos taurus beef cattle. Animal Genetics 2008, 40:176-184.

5. Peng B, Kimmel M: simuPOP: a forward-time population genetics simulation environment. Bioinformatics 2005, 21:3686-3687.

6. Mork J, Bentsen HB, Hindar K, Skaala Ø: Genetiske interaksjoner mellom oppdrettslaks og vill laks. In Til laks åt alle kan ingen gjera. Edited by: Rieber-Mohn GF. Oslo: NOU, Norges Offentlige Utredninger; 1999:9:232-259.

7. Gjedrem T, Gjøen HM, Gjerde B: Genetic origin of Norwegian farmed Atlantic salmon. Aquaculture 1991, 98:41-50.

8. MjøInerød IB, Refseth UH, Karlsen E, Balstad T, Jakobsen KS, Hindar K: Genetic differences between two wild and one farmed population of Atlantic salmon (Salmo salar) revealed by three classes of genetic markers. Hereditas 1997, 127:239-248.

9. Skaala $\varnothing$, Taggart JB, Gunnes K: Genetic differences between five major domesticated strains of Atlantic salmon and wild salmon. Journal of Fish Biology 2005, 67:118-128.

10. Wennevik V, Skaala $\varnothing$, Titov SF, Studyonov I, Nævdal G: Microsatellite variation in populations of Atlantic salmon from North Europe. Environmental Biology of Fishes 2004, 69:143-152.

11. Skaala $\varnothing$, Høyheim B, Glover K, Dahle G: Microsatellite analysis in domesticated and wild Atlantic salmon (Salmo salar L.) allelic diversity and identification of individuals. Aquaculture 2004, 240:131-143.

12. Skaala $\varnothing$, Wennevik $\vee$, Glover K: Evidence of temporal genetic change in wild Atlantic salmon, Salmo salar L., populations affected by farm escapees. ICES Journal of Marine Science 2006, 62:1224-1233.

13. Weir BS, Cockerman CC: Estimating F-statistics for the analysis of population structure. Evolution 1984, 38:1358-1370.

14. Gjedrem T, Baranski M: Selective Breeding in Aquaculture: An Introduction London: Springer 2009

15. Murakaeva A, Kohlmann K, Kersten P, Kamilove B, Khabibullin D: Genetic characterization of wild and domesticated common carp (Cyprinus carpio L.) populations from Uzbekistan. Aquaculture 2003, 178:153-166

16. Kohlmann K, Kersten P, Flajšhans M: Comparison of microsatellite variability in wild and cultured tench (Tinca tinca). Aquaculture 2007, 272S1:S147-S151.

17. Pampoulie C, Jörundsdóttir TD, Steinarsson A, Pétursdóttir G, Stefánsson MO, Daníelsdóttir AK: Genetic comparison of experimental farmed strains and wild Icelandic populations of Atlantic cod (Gadus morhua L.). Aquaculture 2006, 261:556-564.

18. Withler RE, Rundle T, Beacham TD: Genetic identification of wild and domesticated strains of chinook salmon (Oncorhynchus tshawytscha) in southern British Columbia, Canada. Aquaculture 2007, 272S1:S161-S171.

19. Kong L, Qi L: Genetic comparison of cultured and wild populations of the clam Coelomactra antiquata (Spengler) in China using AFLP markers. Aquaculture 2007, 271:152-161.

20. Li J, Wang G, Bai Z: Genetic variability in four wild and two farmed stocks of the Chinese freshwater pearl mussel (Hyriopsis cumingii) estimated by microsatellite DNA markers. Aquaculture 2009, 287:286-291.

21. Houston RD, Haley CS, Hamilton A, Guy DR, Tinch AE, Taggard JB, McAndrew BJ, Bishop SC: Major quantitative trait loci affect resistance to infectious pancreatic necrosis in Atlantic salmon (Salmo salar). Genetics 2008, 178:1109-1115.

22. Moen T, Baranski M, Sonesson AK, Kjøglum S: Confirmation and finemapping of a major QTL for resistance to infectious pancreatic necrosis 
in Atlantic salmon (Salmo salar): population-level associations between markers and trait. BMC Genomics 2009, 10:368.

23. Luikart G, England PR, Tallmon D, Jordan S, Taberlet P: The power and promise of population genomics: from genotyping to genome typing. Nature Reviews 2003, 4:981-994.

24. Ewens WJ: The sampling theory of selectively neutral alleles. Theoretical Population Biology 1972, 3:87-11.

25. Watterson G: The homozygosity test of neutrality. Genetics 1978, 88:405-417.

26. Tajima F: Statistical method for testing the neutral mutation hypothesis by DNA polymorphism. Genetics 1989, 123:585-595.

27. Fu YX: Statistical tests of neutrality of mutations against population growth, hitchhiking and background selection. Genetics 1997, 147:915-925.

28. Sabeti PC, Reich DE, Higgins JM, Levine HZP, Richter DJ, Schaffner SF, Gabriel SB, Platko JV, Patterson NJ, McDonald GJ, et al: Detecting recent positive selection in human genome from haplotype structure. Nature 2002, 419:832-837.

29. Voight BF, Kudaravalli S, Wen X, Pritchard JK: A map of recent positive selection in human genome. PloS Biology 2006, 4:446-458.

30. Lewontin RC, Krakauer JK: Distribution of gene frequency as a test of the theory of the selective neutrality of polymorphisms. Genetics 1973, 74:175-195.

31. Beaumont MA, Nichols RA: Evaluating loci for use in the genetic analysis of population structure. Proceedings of the Royal Society of London Series B, Containing papers of a Biological character 1996, 263:1619-1625.

32. Vitalis $R$, Dawson $K$, Boursot $P$ : Interpretation of variation across marker loci as evidence of selection. Genetics 2001, 158:1811-1823.

doi:10.1186/1756-0500-3-232

Cite this article as: Karlsson and Moen: The power to detect artificial selection acting on single loci in recently domesticated species. BMC Research Notes 2010 3:232.

\section{Submit your next manuscript to BioMed Central and take full advantage of:}

- Convenient online submission

- Thorough peer review

- No space constraints or color figure charges

- Immediate publication on acceptance

- Inclusion in PubMed, CAS, Scopus and Google Scholar

- Research which is freely available for redistribution

Submit your manuscript at www.biomedcentral.com/submit 